\title{
O Sistema Nacional de Combate ao Abuso e à Exploração Sexual Infantojuvenil e o Plano Nacional: um exemplo de política pública aplicada
}

\section{The National System to Combat Sexual Exploitation of Children and Adolescents and the National Plan: a case of public policy}

Thaísa Veras ${ }^{1}$

\begin{abstract}
Resumo
Este artigo tem por objetivo principal tratar de uma política pública aplicada, qual seja, o Sistema Nacional de Combate ao Abuso e à Exploração Sexual Infantojuvenil. Para tanto, inicialmente, é apresentada uma breve definição dos termos, com o intuito de esclarecer a forma como foram interpretados e utilizados no texto. Além disso, é definido o significado de políticas públicas, para que se tenha maior clareza sobre como estas podem auxiliar no entendimento do tema. Por fim, são apresentados os impactos sociais do Sistema Nacional e feito um breve relato sobre o Plano Nacional.
\end{abstract}

Palavras-chave: Sistema Nacional de Combate ao Abuso e à Exploração Sexual Infantojuvenil; políticas públicas; exploração sexual infantojuvenil; Plano Nacional.

\begin{abstract}
The main objective of this article is to deal with public policy, which is the National System to Combat Sexual Exploitation of Children and Adolescents. To this end, initially, some terms are briefly defined in order to elucidate the way that the policy is interpreted and used throughout the text. Furthermore, it defines the meaning of public policy in order to understand how it can help in the understanding of the theme. At the end, the National System's social impacts are shown and there is a short report about the how the National Plan is draw up.
\end{abstract}

Key words: National System to Combat Sexual Exploitation of Children and Adolescents; public policies; sexual exploitation of children and National Plan.

\section{Preliminares}

A conscientização sobre a exploração sexual infantojuvenil, exploração esta que implica a venda de serviços sexuais prestados por crianças ou adolescentes para uma terceira pessoa, apresenta uma história relativamente recente. Todavia, a prevenção e o combate a esse tipo de exploração é objeto de algumas iniciativas e de instrumentos regionais e nacionais. Assim, este artigo busca desenvolver um exemplo de política pública aplicada, qual seja, o Sistema Nacional de Combate ao Abuso e à Exploração Sexual Infantojuvenil, abordando também o impacto social de sua implementação. Além disso, falar-se-á, resumidamente, sobre o Plano Nacional de Enfrentamento da Violência Sexual Infantojuvenil.

Atualmente, percebe-se uma maneira extremamente materialista e consumista de encarar o mundo. Por conseguinte, pode-se observar que os padrões de comportamento e os valores éticos da sociedade também sofreram mudanças profundas. Imagina-se que o mundo seja como um supermercado, onde tudo está à venda, inclusive, a felicidade e, assunto que será aqui trabalhado, o sexo. Acompanhando tal raciocínio, percebe-se porque pedófilos ou qualquer delinquente sexual sentem-se no direito de "comprar" uma criança ou adolescente, com o intuito de satisfazer seus desejos sexuais. Ademais, é natural que esse pensamento provoque uma crise de valores morais na sociedade como um todo.

Artigo submetido em agosto de 2008 e aceito para publicação em outubro de 2009.

1 Mestre em Administração Pública pela EBAPE/FGV, Instituição: Rio de Janeiro Refrescos (fábrica da Coca-Cola no Rio de Janeiro), e-mail: thaisa_veras@hotmail.com 
Mesmo assim é importante ressaltar que essa vinculação de crianças e adolescentes à atividade de exploração sexual se dá pela combinação de diversos fatores de risco, podendo ser tanto em relação à demanda, quanto em relação à oferta. Feita a constatação da realidade, cabe ressaltar que este artigo consiste em uma exemplificação desta, na medida em que trata de uma política pública aplicada, qual seja, o Sistema Nacional de Combate ao Abuso e à Exploração Sexual Infantojuvenil e de seus impactos sociais, além do Plano Nacional.

\section{Definição dos termos}

Inicialmente, vale salientar que a tomada de consciência da exploração sexual infantojuvenil deu-se em 1996, no período entre 27 e 31 de agosto, quando da organização do "Primeiro Congresso Mundial contra a Exploração Sexual Comercial Infantil", em Estocolmo, capital sueca. Tal evento contou com a participação de 122 países e a união de diversos atores, entre eles: a Rede Internacional de Organizações contra a Exploração Sexual da Infância (ECPAT), o Fundo das Nações Unidas para a Infância (Unicef), um grupo de ONGs e o governo da Suécia.

Nesse congresso, adotou-se a chamada "Agenda de Estocolmo", que consiste na reunião das recomendações definidas no evento no que diz respeito ao enfrentamento do problema. Ademais, esse documento reforça sua importância, visto que seu conteúdo tem sido utilizado para orientar a criação de planos de ação nacional de combate à violência contra crianças e adolescentes.

Cabe, neste momento, salientar que, de acordo com o Estatuto da Criança e do Adolescente (ECA) - que substituiu o Código do Menor e é a regulamentação deste artigo -, criança é a pessoa com até 12 anos de idade incompletos, sendo tratada, pelas leis brasileiras, como em condição especial de desenvolvimento, merecedora de atenção prioritária, tanto por parte da sociedade, quanto da família e do Estado. Analisando outra vertente, vale ressaltar que:

Os estudos socioculturais na América Latina tenderam a ignorar a dimensão de geração: tanto os estudos sobre as comunidades indígenas, como os centrados em sociedades rurais e urbanas, tendem a ver os sujeitos de estudo como índios, camponeses, colonos, homens, mulheres, burgueses, operários, mas não como crianças e menos ainda como jovens. Quando os menores foram salientados, surgem como portadores ou vítimas de determinados "problemas sociais": violência, drogas, abandono, pobreza etc. (PAMPOLS, 2007)

É importante atentar para o fato de que, na citação anterior, a palavra "menores" foi grifada, propositalmente, com o intuito de esclarecer que esta é uma "expressão utilizada na legislação anterior à doutrina de proteção integral para designar a população abaixo de 18 anos" (OIT/IPEC, 2007). Todavia, atualmente, essa palavra é vista com sentido negativo, discriminatório, considerando que se refere às crianças e adolescentes de acordo com suas necessidades ou comportamento, sendo geralmente usada num contexto de desvalorização do adolescente; por exemplo, menor infrator, menor carente, menor abandonado. Por isto, as leis nacionais e internacionais não consideram mais esse termo.

Para o mesmo estatuto, o ECA, adolescente é a pessoa entre 12 e 18 anos incompletos, período da vida caracterizado por mudanças corporais e psicológicas que se estende, aproximadamente, até os 20 anos. Por outro lado, segundo a definição das Nações Unidas, é considerada jovem toda aquela pessoa entre 15 e 24 anos. Ademais, deve ser assegurado tanto aos adolescentes quanto aos jovens (que em determinada idade se confundem) que suas opiniões serão consideradas, através de uma ativa participação em prol da garantia do respeito aos seus direitos.

Além disso, os governos de cada país participante do congresso de 1996 na Suécia que assinaram a Declaração e o Programa de Ação de Estocolmo - reforçada pelo Compromisso Mundial de Yokohama (2001) respondem pela formulação desses planos de ação nacional, cujo objetivo é mobilizar e orientar outros setores na busca pela erradicação da exploração sexual de crianças e adolescentes. Como exemplo de outra de suas contribuições, a "Agenda de Estocolmo" produziu a definição que se segue: 
A exploração sexual de crianças e adolescentes é uma violação fundamental dos direitos. Abrange o abuso sexual por parte do adulto, e remuneração em dinheiro ou em espécie para a criança/adolescente ou para um terceiro ou várias pessoas. A criança ou adolescente é tratada como objeto sexual ou mercadoria. A exploração sexual constitui uma forma de coerção e violência contra a infância e adolescência, equivale a trabalho forçado e constitui uma forma contemporânea de escravidão. (OIT/IPEC, 2007)

Percebe-se que na exploração sexual há uma vantagem comercial, onde as crianças protagonizam o papel de vítimas e não o de autoras. Nesse sentido, Leal (2003) define exploração sexual de crianças e adolescentes como:

uma relação de mercantilização (exploração/dominação) e abuso (poder) do corpo de crianças e adolescentes (oferta) por exploradores sexuais (mercadores), organizados em redes de comercialização local e global (mercado), ou por pais ou responsáveis, e por consumidores de serviços sexuais pagos (demanda). (LEAL, 2003)

Relacionados à demanda, temos ainda os exemplos que seguem:

a existência de redes organizadas de recrutamento e outros intermediários que se beneficiam economicamente dessa atividade;

as novas tecnologias de comunicação que dão agilidade a exploradores, permitindo a ampliação desse negócio ilegal;

a tolerância social;

autoridades que não cumprem seu papel na proteção das crianças e dos adolescentes;

legislações débeis ou não aplicadas; além da

corrupção e da impunidade.

Quanto à oferta de crianças e adolescentes à exploração sexual, tantos outros podem exemplificar, tais como:

pobreza e exclusão social;

acirramento da desigualdade social;

trabalho infantil;

políticas sociais débeis e ineficazes;

violência intrafamiliar;

falta de perspectiva para adolescentes e jovens;

baixa qualidade da educação; e

debilidade das respostas sociais ao combate à exploração sexual infantojuvenil.

A exploração sexual fere os direitos fundamentais, a partir do momento em que estes não estão sendo respeitados e garantidos. Além disso, a exploração sexual se coloca no campo da negação de um direito inalienável: o da soberania e autonomia sobre a vida e sobre o próprio corpo, que deve ser, acima de qualquer fato, protegido para o pleno desenvolvimento. Ademais, a sexualidade, enquanto atividade sexual deve ser exercida de forma igualitária e simétrica, como uma livre opção e não como uma mercadoria valorizada pelas injunções econômico-sociais. (DOS SANTOS, 2004)

Desse modo, sabe-se que, frequentemente, diversas crianças e adolescentes são afastados de suas famílias com promessas de um futuro melhor, acabando por serem vítimas de exploração sexual. Esse tráfico de crianças e adolescentes para a exploração sexual realizado por quadrilhas organizadas está intimamente relacionado ao tráfico de drogas, sendo muitas vezes realizado pelas mesmas redes e rotas. 
Diversos estudos têm demonstrado que a exploração sexual infantil é sustentada por redes delituosas, articuladas e organizadas, da qual podem participar traficantes, taxistas, donos ou empregados de bares e hotéis, agências de turismo, agências de modelo, turistas, executivos em viagem, entre outros. (OIT/IPEC, 2007)

Além do mais, existe a exploração sexual no turismo, uma atividade ilegal praticada por pessoas que conduzem visitantes a destinos turísticos, oferecendo-lhes relações sexuais com crianças e adolescentes da região visitada. Infelizmente, a ideia de que explorar sexualmente uma criança ou adolescente não resultará em sanção alguma é um dos principais estímulos à execução desse delito; pois, quando há uma legislação clara, um sistema de justiça que funciona regularmente, operadores com capacidade de fazer cumprir a legislação, exemplos concretos de aplicação das leis e uma sociedade vigilante, as possibilidades de inibir a ação dos delinquentes sexuais aumentam sensivelmente.

A violência sexual cometida contra crianças e adolescentes (que abrange todo o espectro que vai desde as relações abusivas sem trocas comerciais às explicitamente monetárias) emerge do cenário socioeconômico (contradições de classe social) e político atual (violência estrutural), apoiado em valores culturais que reforçam práticas discriminatórias, tais como o preconceito relacionado a gênero (o patriarcalismo), à geração (adultocentrismo) e à raça/etnia (apartheid social), em detrimento de práticas sociais voltadas à garantia e defesa dos direitos dessa população. As práticas discriminatórias geram barreiras físicas, culturais, sociais e morais que resultam na exclusão em massa de grande parte da população. (HAZEU; FONSECA, 1998)

Outra visão do chamado turismo sexual é fornecida pela Organização Mundial de Turismo (OMT), que o descreve como viagens organizadas que se valem das estruturas da indústria do turismo, com o intuito de, principalmente, facilitar o comércio sexual entre turistas e nativos. Vale notar que essa acepção não considera a questão da legalidade das atividades promulgadas, concentrando-se apenas nas práticas e nos objetivos dos turistas, presumindo que estes possam ser distinguidos, de maneira clara, dos turistas "normais" (SILVA; BLANCHETTE, 2005).

Já abuso sexual pode ser definido como uma violência contra crianças e adolescentes, geralmente, praticada por pessoas em quem confiam, dentro ou fora da família, para obter satisfação sexual. Normalmente, essas pessoas se encontram em situação de vulnerabilidade social, ou seja, numa situação de precariedade das relações socioeconômicas, culturais e afetivo-emocionais. "Estes contatos ou interações sexuais podem ocorrer mediante força, promessas, coação, ameaças, manipulação emocional, enganos ou pressão" (SUBGROUP..., 2005). Esses contatos podem ser físicos, verbais ou emocionais, incluindo o voyeurismo, que consiste em espionar, com intuitos sexuais, crianças e adolescentes em banheiros ou em seus quartos. É importante ressaltar que, nos últimos anos, foram registrados significativos avanços no que diz respeito à consciência profissional e comunitária sobre essas situações relacionadas à sexualidade de crianças e adolescentes.

\section{A gênese de uma política pública}

Entende-se por gênese uma série de fatos e causas que concorreram para a formação de algo relevante que, neste caso, é a política pública. Para tanto, é importante, primeiro de tudo, definir o significado de política pública, a fim de melhor compreender seu objetivo. Nesse sentido, Lynn (1980, apud SOUZA, 2002) a define como um "conjunto específico de ações do governo que irão produzir efeitos específicos", enquanto Dye (1984 apud SOUZA, 2002) afirma ser "o que o governo escolhe fazer ou não fazer".

Além disso, Peters (apud SOUZA, 2002) acredita que "política pública é a soma das atividades dos governos, que agem diretamente ou através de delegação, e que influenciam a vida dos cidadãos". Ademais, de acordo com Souza (2002):

as políticas públicas, no Brasil, sofrem inúmeras restrições financeiras e políticas impostas aos governos, com a adoção de políticas restritivas de gastos, a ênfase no ajuste fiscal e a demanda por elaboração de políticas eficientes e efetivas. 
Todavia, apesar de inúmeras definições, sabe-se que no Brasil há certa dificuldade no que diz respeito ao desenho de políticas públicas capazes de impulsionar o desenvolvimento econômico e promover a inclusão social. Portanto, pode-se dizer que o processo de formulação de uma política pública é aquele pelo qual o governo transparece seus propósitos em programas e ações, a fim de que estes produzam resultados e, consequentemente, mudanças desejadas. Nesse sentido, é essencial que se atribua à participação da sociedade a mesma importância dispensada aos objetivos públicos, a fim de que estes sejam alcançados. Buscando compreender essa sinergia, Jacobi (2002) afirma que:

A partir do final dos anos 1960, a noção de participação cidadã ganha importância, evidenciando a necessidade de arranjos institucionais que estimulem, desde a esfera estatal, a criação de canais de comunicação com a sociedade e permitindo que de alguma forma se amplie a esfera de engajamento dos cidadãos. (JACOBI, 2002)

É nesse período que surge a preocupação com a efetiva participação da sociedade em temas antes restritos à esfera pública. Nos anos 1980, a participação cidadã, com sua importância devidamente reconhecida, é então evidenciada como um instrumento facilitador do aprofundamento da democracia. Dessa forma, inicia-se um processo de descentralização, incentivando transformações no que diz respeito à dinâmica de participação das pessoas na formulação e implementação de políticas públicas voltadas ao cumprimento dos direitos sociais.

Na América Latina, a luta pela conquista de espaços para aumentar a participação social é, sem dúvida, um dos aspectos mais desafiadores para a análise do alcance da democracia nas relações entre o nível local de governo e a cidadania. Na década de 1990, na América Latina, a participação vem sendo amparada e institucionalizada em suas diversas dimensões no âmbito das democracias representativas. A participação popular se transforma no referencial não só para ampliar as possibilidades de acesso dos setores populares, segundo uma perspectiva de desenvolvimento da sociedade civil e de fortalecimento dos mecanismos democráticos, mas também para garantir a execução eficiente de programas de compensação social no contexto das políticas públicas de ajuste estrutural e de liberalização da economia e de privatização do patrimônio do Estado. (JACOBI, 2002)

Como se observa na citação de Jacobi, foi na década de 1990 que efetivamente se passou a buscar o que havia sido projetado, ou seja, um modelo institucional redistribuidor, focado não somente no reconhecimento, mas também no exercício dos direitos sociais dos cidadãos. Cabe salientar que esse novo modelo constitui, portanto, um grande desafio para as políticas públicas. Isso ocorre quando se estimula cada cidadão, o governo (em seus vários níveis) e as organizações internacionais a combater, por exemplo, situações de violência que se manifestam tanto pela mercantilização da sexualidade de crianças e adolescentes quanto pelas relações de poder que envolvem esse tipo de exploração sexual.

Em primeira instância, a noção de público tem significado topográfico e normativo. Em seu sentido normativo, remete ao que pertence a todos e, consequentemente, interessa a todos. É preciso interpelar, portanto, a sociedade. Em seu sentido topográfico, por outro lado, o conceito considera os espaços em que pode ser realizado. "Onde são adotadas as decisões que interessam a todos?" e "A quem cabe produzir e proteger os bens públicos?" são perguntas que, tradicionalmente, interpelam o Estado, mas que, cada vez mais, cabe à sociedade fazer. Remeter ao conceito de público é aludir, num mesmo movimento, tanto à sociedade como ao Estado. O público, porém, não é dado: é um processo de construção. Por outro lado, supõe assumir a possibilidade de que a sociedade se autogoverne, mediante um Estado democrático. $O$ Estado é virtualmente considerado, portanto, como espaço de realização do público, mas só na medida em que represente a sociedade e possibilite que ela se desenvolva. Por outro lado, o público remete à autorrealização da sociedade e, portanto, aponta para a possibilidade de que as necessidades coletivas sejam autonomamente satisfeitas a partir da sociedade, mas sem que isso implique que o Estado abdique de suas responsabilidades. Assim, pois, por este enfoque, o nó crítico a ser investigado é o caráter das relações entre Estado e sociedade, com a sociedade - não o Estado - no papel de protagonista. (GRAU, 1998) 
Visando à execução de políticas descentralizadas, o governo adota como principal estratégia as parcerias com ONGs, a fim de que projetos e programas sejam efetivamente viabilizados e implementados. Além disso, Leal (2001) acredita que na busca incessante pela obtenção de legitimidade e de condições de governabilidade, o Estado sustenta um discurso crítico, apoiando-se na experiência da sociedade civil organizada. Entretanto, o Estado igualmente buscaria a despolitização da sociedade, tendo em vista que a subordina às metas de ajuste fiscal, minimiza recursos e fortalece o mercado, numa perspectiva de descentralização do poder - ao transferilo para instâncias locais - como forma de partilhar responsabilidades e custos das políticas sociais.

Os programas e ações do governo, em parceria com a sociedade civil, tendem para uma precarização das políticas sociais porque dependem de convênios que não garantem a continuidade dos mesmos, uma vez que são datados, o que configura a fragilidade da resposta ao fenômeno. (LEAL; CÉSAR, 2005)

Desse modo, observa-se até o final da década de 1990, por parte do Poder Executivo, responsável pela formulação de políticas públicas, uma definição pouco consistente do que seja enfrentamento da exploração sexual de crianças e adolescentes. Ademais, o relatório elaborado pelo Cecria (FALEIROS, 1997) sinalizava uma situação de descontinuidade na aplicação dos recursos, além de estratégias inconsistentes. Todavia, Vianna (2003) afirma que, apesar das medidas legislativas e da mobilização social serem essenciais ao enfrentamento, não são suficientes para garantir a integridade e o bem-estar das crianças e adolescentes. Dessa forma, entendese ser essencial à efetivação desses direitos, a disponibilidade de recursos para financiamento dos programas e projetos que trabalhem nesse sentido.

Vale salientar que a preocupação com a erradicação da exploração sexual infantojuvenil somente foi incorporada ao orçamento federal recentemente, a partir do Plano Plurianual (PPA 2000-2003), transformandose então em política nacional. Tal inclusão buscou responder ao movimento que na época se formava no país e que culminou na elaboração do Plano Nacional de Enfrentamento da Violência Sexual Infantojuvenil, aprovado no ano 2000, buscando a integração de iniciativas existentes e a elaboração de novas e eficientes estratégias de ação.

No dia 3 de janeiro de 2003 o presidente do Brasil, Luiz Inácio Lula da Silva, determinou, entre outras medidas tomadas no primeiro encontro ministerial do governo, que o então ministro da Justiça, Márcio Thomaz Bastos, priorizasse o combate à exploração sexual infantojuvenil e procedesse ao fechamento de estabelecimentos que propiciassem esse tipo de atividade.

Dando prosseguimento aos fatos, Márcio Thomaz Bastos anunciou a criação da Comissão Estadual Interinstitucional de Enfrentamento da Violência Sexual de Crianças e Adolescentes, com representantes dos ministérios da Educação, da Saúde, da Justiça, do Turismo, das Cidades e da Segurança Alimentar e Combate à Fome, bem como das secretarias dos Direitos Humanos e de Políticas para a Mulher.

É importante ressaltar que essa comissão é resultado de uma das resoluções propostas pelo Plano Nacional, objetivando a orientação da sociedade no que diz respeito à exploração e a outras formas de abuso sexual, além de desenvolver ações visando ao aumento de eficiência dos postos de atendimento a meninos e meninas que tenham sofrido abuso sexual. Ademais, essa comissão é composta por membros de organizações nãogovernamentais (ONGs), da Ordem dos Advogados do Brasil (OAB), de técnicos da Secretaria de Estado do Trabalho, Emprego e Promoção Social, da Secretaria de Turismo, da Secretaria de Segurança Pública e de representantes do Conselho Estadual da Criança e do Adolescente, que se reúnem mensalmente a fim de estabelecer estratégias de atuação.

Cabe lembrar que Márcio Thomaz Bastos declarou que buscaria a contribuição das ONGs que atuam nessa área. No entanto, a primeira medida que tomou foi transferir para a área governamental o Sistema Nacional de Combate ao Abuso e Exploração Sexual Infantojuvenil, operado até aquele momento pela ONG Abrapia (Associação Brasileira Multiprofissional de Proteção à Infância e à Adolescência) em convênio com o Ministério da Justiça. Em 14 de maio de 2003, a Secretaria Especial dos Direitos Humanos (Sedh) passou a operar o número 0800-99-0500, antes sob responsabilidade da Abrapia. 
Em suma, pode-se dizer que atualmente é impossível tratar de políticas públicas voltadas à área da infância e adolescência sem mencionar a importância do enfoque na participação ativa da sociedade civil. Dessa forma, obrigatoriamente, a inserção do tema de exploração sexual infantojuvenil, tanto no cenário político quanto no desenvolvimento de ações voltadas para a temática, contou com a forte influência exercida pela mobilização da sociedade.

\section{Sistema Nacional de Combate ao Abuso e à Exploração Sexual Infantojuvenil}

A instituição do Estatuto da Criança e do Adolescente (1990) estabeleceu princípios em consonância com a Constituição Federal promulgada em 1988 (BRASIL, 1988) e com a Convenção Internacional dos Direitos das Crianças e Adolescentes aprovada em 1989, três fatos que trouxeram novos paradigmas à questão dos direitos infantojuvenis. Dessa forma, crianças e adolescentes foram dissociados da imagem de objetos de sanções e a questão do abuso e da exploração sexual passou a ser tratada pela sociedade, pela academia e por autoridades (principalmente, pelo Poder Judiciário e pela polícia) como de natureza pública e não privada.

Também foram observadas mudanças na forma de abordagem da problemática infantojuvenil brasileira provocadas pelo ECA que, consequentemente, trouxeram modificações nas políticas públicas voltadas às crianças e adolescentes. Pelo novo estatuto, as crianças passaram à condição de sujeitos de direito, o que fez com que políticas e programas começassem a focar a proteção, a prevenção e o combate à violação desses direitos.

Entre os princípios instituídos pelo ECA estão a descentralização político-administrativa e a participação da população no que se refere às políticas públicas de proteção infantojuvenil, convergindo com a $\mathrm{CF} / 88$. Isso gerou a inclusão dos municípios no sentido de incorporar o papel de agente na proteção dos direitos das crianças e adolescentes, via políticas públicas e criação dos conselhos paritários e deliberativos nos três níveis da Federação.

Nesse sentido, em 1997, numa ampla parceria da Associação Brasileira Multiprofissional de Proteção à Infância e à Adolescência (Abrapia) com atores do poder público, é criado o Sistema Nacional de Combate ao Abuso e à Exploração Sexual Infantojuvenil. Operacionalizada por meio de um serviço telefônico gratuito (0800-99-500), essa parceria tem como objetivo ampliar as denúncias de abuso e exploração sexual infantojuvenil, buscando ser reconhecida por sua contribuição para o combate ao abuso e à exploração sexual. Cabe salientar que a Abrapia é uma sociedade privada com fins públicos e reconhecida como de utilidade pública federal, estadual e municipal. Trata-se de uma organização não-governamental fundada em 1988, que trabalha na promoção e na defesa dos direitos da criança e do adolescente.

Quanto ao Sistema Nacional, este surgiu como uma campanha pontual promovida pelo Instituto Brasileiro de Turismo (Embratur) em parceria com o Ministério da Justiça - especialmente, no período de Carnaval - para combater uma modalidade específica de exploração sexual infantojuvenil, o chamado turismo sexual. Para tanto, a campanha teve suas bases estabelecidas em 1995, sendo intitulada "Campanha Nacional pelo Fim da Exploração, Violência e Turismo Sexual contra Crianças e Adolescentes". Por sua importância, rapidamente evoluiu e passou a constituir um programa efetivamente sistematizado, cujo foco no tema "Abuso e Exploração Sexual Infantojuvenil" foi mantido, embora tenha deixado de priorizar o combate, voltando-se para a prevenção e a denúncia de abusos e da exploração sexual de crianças e adolescentes. Portanto, a ênfase deveria ser dada a um trabalho educativo com pais, familiares, profissionais de saúde, professores e lideranças comunitárias atores que geralmente testemunham ou têm conhecimento de casos.

Além desses atores, existem ainda outros grupos com a mesma função de prevenir e denunciar tais atividades, cada qual em seu âmbito específico, quais sejam: mídia, governo e empresas privadas. A mídia tem o dever de fornecer à sociedade uma cobertura responsável e comprometida com os direitos das crianças e adolescentes, fazendo bom uso de suas imagens e reforçando a necessidade de denúncia nos casos de atividades ilícitas. $\mathrm{O}$ governo, por sua vez, é responsável pela formulação de políticas públicas visando ao combate de delitos dessa 
natureza. Por fim, às empresas privadas cabe a responsabilidade social corporativa, por meio do código de conduta. Segundo Tenório (2004):

Vários autores têm focos diferentes para definir responsabilidade social, mas são unânimes no que concerne à prática ativa de ações sociais para desenvolvimento da comunidade. Portanto, responsabilidade social corporativa é um compromisso da empresa com a sociedade e sua cadeia produtiva, clientes, fornecedores, comunidades e meio ambiente, na busca da melhoria da qualidade de vida da comunidade.

Desta maneira, o Sistema Nacional foi operacionalizado por meio de um esforço para manter a sociedade informada sobre o problema, incentivando-a a denunciar. Para isso, foi disponibilizado um número telefônico gratuito, de cobertura nacional, assegurando-se o sigilo da identidade do denunciante. Dessa forma, no período de 1997 a 1999, o serviço de recebimento de denúncias (0800) operado pela Abrapia esteve voltado, exclusivamente, para o combate à exploração sexual infantojuvenil, registrando denúncias relacionadas ao abuso sexual contra crianças e adolescentes somente a partir do ano 2000.

Nos três primeiros anos de funcionamento do Sistema Nacional (1997-1999), a Abrapia constatou que o chamado turismo sexual não constituía a principal forma de exploração sexual de crianças e adolescentes; pelo contrário, representava um percentual pequeno em relação às demais formas de violência infantojuvenil. Em vista disso, a Embratur, principal patrocinadora do Sistema, retirou-se da linha de frente da operação. Nesse aspecto, é importante questionar o que foi levado em consideração ao se definir o número de denúncias como "percentual pequeno", tendo em vista que um único caso de exploração sexual já é suficiente para preocupações e tratamento rigoroso.

Assim, em 14 de maio de 2003, o Sistema Nacional deixou de ser operacionalizado pela Abrapia, tornando-se uma política pública de âmbito federal, a cargo da Secretaria Especial de Direitos Humanos (Sedh), diretamente ligada à Presidência da República, o que, certamente, é um forte indicador da preocupação do presidente com o tema. Tal preocupação é reforçada pela realização do $3^{\circ}$ Congresso Mundial de Enfrentamento da Exploração Sexual de Crianças e Adolescentes, de 25 a 28 de novembro de 2008, na cidade do Rio de Janeiro. Naturalmente, a escolha do Brasil como sede do congresso evidencia o reconhecimento internacional dos avanços das estratégias adotadas no país.

Cabe salientar que tal modificação deveu-se ao fato da Brasil Telecom adquirir a responsabilidade pelo número, em detrimento da Embratel, também interessada. Desse modo, a Secretaria Especial de Direitos Humanos da Presidência da República, em parceria com a Anatel e empresas de telefonia, disponibilizou o número 100, substituindo o 0800-99-0500. A fim de evitar perda de qualidade e eficiência do serviço em virtude da troca dos números, foi decidido que durante um mês essa mudança seria notificada nas ligações realizadas para o 0800 .

O Disque-Denúncia (disque-100) é um sistema de denúncia por telefone que prima pelo combate aos maustratos, ao abuso e à exploração sexual infantojuvenil no Brasil. Dessa forma, qualquer pessoa, de qualquer lugar do país tem acesso ao disque-100 e deve utilizá-lo sempre que necessário, a fim de tornar as denúncias de conhecimento de autoridades ou de organizações responsáveis pela proteção das crianças e adolescentes. A polícia é acionada, comunicando imediatamente ao Ministério Público, que por sua vez informa o Poder Judiciário, resultando na responsabilização do agressor e na proteção da vítima.

Além disso, existe uma alternativa a partir do momento em que a denúncia é realizada por meio do disque-100, qual seja, o encaminhamento à Comissão Estadual Interinstitucional de Enfrentamento da Violência Sexual de Crianças e Adolescentes. Em seguida, a denúncia segue para o Conselho Tutelar da Criança e do Adolescente (onde ocorre uma votação com participação da comunidade), que, por sua vez, dará início a um inquérito policial a ser encaminhado ao Ministério Público. Este informa o Poder Judiciário, que cuidará da responsabilização do agressor e da proteção da vítima.

Todavia, é importante ressaltar que o Disque-Denúncia não é o único instrumento de denúncia disponível para a sociedade. Existem algumas possibilidades em relação aos caminhos que a denúncia, partindo do cidadão, 
percorre. Por exemplo, o cidadão pode fazer sua denúncia diretamente ao Conselho Tutelar da Criança e do Adolescente, e a partir daí, o caminho é exatamente o mesmo que o descrito no parágrafo imediatamente anterior.

Outra maneira de denunciar é comunicar diretamente à polícia civil, que ficará encarregada de repassar a informação ao Ministério Público. Em seguida, a denúncia é direcionada ao Poder Judiciário, que se compromete a realizar trâmites tanto de responsabilização do agressor quanto de proteção da vítima.

Ademais, nas delegacias de Proteção à Criança e ao Adolescente, nos conselhos tutelares ou nas instâncias responsáveis pela Justiça do município também são recebidas denúncias referentes a esse tipo de delito. É importante ressaltar que, qualquer que seja o meio de comunicação, a identificação não é requerida para que o fato denunciado seja objeto de investigação pelas autoridades responsáveis, considerando que a maioria das denúncias são originadas de membros da família e que há certo receio em denunciar, pois em grande parte dos casos o aliciador é o provedor da família.

No caso do abuso sexual, o silêncio das vítimas muitas vezes prevalece e denúncias deixam de ser registradas. Isso acontece em consequência do tabu de lidar com um fenômeno que tem origem, na grande maioria dos casos, no seio da família. Por esse mesmo motivo, identificar a ocorrência do abuso por meio de pesquisa em domicílios é tecnicamente inviável. Já em relação à exploração sexual, a clandestinidade, a mobilidade dos exploradores e a coerção velada do crime organizado são as principais barreiras para traçar a abrangência do problema. (BRASIL, 2006)

Dessa forma, por vezes, a pessoa que sofreu o abuso deseja revelar o problema, mas teme as consequências, como, por exemplo, que se cometa o mesmo abuso com um irmão mais novo.

Em outros casos, o carinho que a vítima ainda nutre pelo agressor, no caso de um parente, pode servir de impedimento para que ela o denuncie. Mas a psicóloga afirma que a criança tende a dar sinais de que foi abusada. Afirma ainda que todo pai deve atentar para sinais como anorexia ou ganho excessivo de peso. Eles podem significar que a criança ou adolescente está tentando acabar com a atração que exerce no agressor. (REPORTAGEM ESPECIAL, 2005)

Nesse sentido, sabe-se que há certa dificuldade em dar continuidade a um crime de direito privado, pois, por exemplo, quando a mãe denuncia o marido por abusar de sua filha, ela não leva em consideração que é ele o provedor da família. Com base nesse fato, dias depois, ela geralmente retira a queixa. Por outro lado, uma vez que a queixa seja feita e o crime registrado como de direito público, essa queixa não poderá ser retirada, devendo ser salientado, porém, que cabe ao delegado definir se o crime é de direito público ou privado.

Outro fato importante é que diversas adolescentes exploradas sexualmente apresentam um histórico de abortos naturais ou provocados, geralmente, com graves implicações para sua saúde, o que, dependendo do caso, envolve risco de morte. Ademais, sequelas de abortos provocados podem trazer dificuldades para uma futura gravidez (ou mesmo impossibilitá-la) quando essas vítimas estiverem em condições físicas, sociais e econômicas de serem mães.

Além da gravidez indesejada, há o risco de infecção com doenças sexualmente transmissíveis, incluindo a aids. A esmagadora maioria das crianças e adolescentes que sofrem ou sofreram exploração sexual é adepta do silêncio. Todavia, além do silêncio das vítimas, existe também o silencio por parte da sociedade, percebido pelo índice (crescente, mas ainda insatisfatório) de denúncias registradas. É essa abstenção a principal cúmplice da exploração e abusos sexuais praticados contra crianças e adolescentes.

Dessa forma, a conscientização por parte da sociedade é essencial, na medida em que seu comprometimento e ação são os elementos que impulsionam os resultados. Junto com a conscientização, cresce (mesmo timidamente) não apenas a quantidade de denúncias recebidas a cada ano, mas também o número de investigações sobre os que aliciam e os que fazem uso do serviço. Segundo reportagem especial disponível no site da Rádio Câmara FM: 
O disque-denúncia de violência, abuso e exploração sexual de crianças e adolescentes da Secretaria Especial dos Direitos Humanos recebeu, de maio de 2003 a abril de 2005, cerca de 10 mil denúncias. Dessas, 3 mil e 200 eram de abuso sexual, contra mil e 700 de exploração sexual. (REPORTAGEM ESPECIAL, 2005)

Por outro lado, quando se analisa a eficiência do Disque-Denúncia, é preciso levar em conta se houve alguma alteração na estrutura etária da população, pois o número de denúncias pode ter aumentado em decorrência do crescimento populacional. Sabe-se que quando aumenta o número de denúncias, o problema da exploração sexual de crianças e adolescentes fica mais visível, chamando a atenção do Estado.

Todavia, o ideal é o que número de denúncias (não o número de delitos) cresça consideravelmente. Isso exerceria uma pressão para que o Estado combata mais incisivamente o problema, que, tendo atingido um índice próximo de zero, sinalizaria uma atividade governamental eficiente. Nesse ponto, cabe salientar que o número de denúncias beirar o zero não significa que o problema tenha sido resolvido, pois é dever do governo continuar agindo, levando-se em conta que a ocorrência de um caso de exploração sexual de crianças e adolescentes já significa que ainda há o que combater.

Neste momento, deve-se ressaltar a importância de serem incluídos componentes de capacitação em projetos, programas ou políticas que remetam à prevenção e à erradicação de delitos, para que tenham êxito as intervenções que visam coibir a exploração sexual de crianças e adolescentes. Desse modo, torna-se essencial capacitar os operadores do sistema, para que dominem e saibam aplicar corretamente a legislação pertinente, considerando que ser detentor do modelo de atendimento correto é essencial para o bom funcionamento desse instrumento, dificultando a ação dos que se valem do disque-100 para aplicar trotes.

Além disso, a exigência de capacitação deve abranger todos os envolvidos no processo, por ser comum crianças e adolescentes vítimas de violência sexual desenvolverem um comportamento agressivo em relação a outras crianças ou adultos próximos, como forma de expressar sua revolta pelas agressões sofridas. Essa agressividade, geralmente, dificulta a adoção de medidas de proteção, o que pode ser contornado, à medida que o pessoal encarregado de lidar com situações desse tipo seja devidamente treinado. Por exemplo, pessoas do setor educacional responsáveis não apenas pela sensibilização para o problema nas escolas e sua prevenção, mas também por detectar possíveis casos, providenciando o encaminhamento necessário, e por atuar como facilitadoras da reinserção escolar dessas crianças e adolescentes vitimas da exploração sexual. Desse modo,

se não há um processo sistemático de capacitação para fortalecimento institucional de todas as organizações públicas e privadas e de todos os profissionais envolvidos sobre as formas corretas de como trabalhar na prevenção do problema, na proteção das crianças e adolescentes e na punição dos delinquentes sexuais, as intervenções tendem ao fracasso. (OIT/IPEC, 2007)

Na realidade, a instrumentalização de todos os envolvidos é o que propicia resultados significativos, à medida que estes passam não somente a estimular denúncias por meio da sensibilização, como também a trabalhar no sentido da prevenção. Dessa forma, a ação do disque-100 pode ser potencializada mediante a efetiva participação desses atores, o que confirma o poder que a comunicação tem de impulsionar uma política pública.

Nesse ponto, foram três os requisitos básicos na busca da ação preventiva do disque-denúncia: a informação e educação, a provisão de serviços de atendimento e a criação de um ambiente social favorável. Com base nesses requisitos, a concretização do programa se deu por meio de ações como, por exemplo, atividades contínuas e sistematizadas a fim de orientar à população sobre como proceder ao presenciar ou ter conhecimento de casos de abuso e/ou exploração sexual infantojuvenil.

Foi feita também a edição e distribuição de material informativo-educativo para a sociedade, além de terem sido realizadas palestras e encontros com representantes de associações de moradores e de unidades de saúde. Além disso, com o intuito de motivar líderes políticos, governamentais, institucionais e comunitários, estes foram convidados a participar de seminários, audiências e palestras. Enfim, a disseminação do disque-100 abrangeu todo o país através de entrevistas a jornais, revistas, emissoras de rádio e televisão e também a websites. 
Embora o fenômeno do abuso e da exploração sexual de crianças e de adolescentes tenha tido maior visibilidade nos últimos anos, por intermédio de denúncias públicas e de campanhas, ainda é difícil de ser quantificado, considerando que se manifesta de formas variadas e não se restringe a uma determinada região, estado ou cidade. Desse modo, a doutrina da proteção integral a crianças e a adolescentes, preconizada na Constituição Federal de 1988, requer, por parte do Estado, ações efetivas e articuladas, nos diferentes níveis da esfera pública, que garantam às crianças e aos adolescentes o direito à liberdade, à dignidade, ao respeito; enfim, à cidadania.

\section{Impacto social da implementação do Sistema Nacional de Combate ao Abuso e à Exploração Sexual Infantojuvenil}

Como visto, o Sistema Nacional de Combate ao Abuso e à Exploração Sexual Infantojuvenil operado pela Associação Brasileira Multiprofissional de Proteção à Infância e à Adolescência (Abrapia) apresentou resultados expressivos, apesar de ainda tímidos. No período entre fevereiro de 1997 e fevereiro de 2003, justamente, a época do convênio entre a associação e o Ministério da Justiça, "a central de atendimento da Abrapia registrou 55.706 ligações, das quais se incluem 5.054 que efetivamente serviram à apresentação de denúncias de violência sexual, em todas as suas formas, contra crianças e adolescentes" (ABRAPIA, 2004).

Por outro lado, as ligações que não se destinavam a denúncias, eram de pessoas buscando esclarecimentos sobre o serviço, procurando melhor entender os conceitos de abuso e de exploração sexual infantojuvenil; quando não queriam saber como confirmar um suspeita para, depois, relatá-la. É válido salientar que, mesmo quando não se tratava de denúncias, as ligações eram importantes, pois colaboravam para o bom funcionamento do sistema, considerando que demandavam uma atitude efetiva diante da situação, atuando de fato como uma campanha de sensibilização e de mobilização social.

Neste momento, cabe ressaltar que campanhas de sensibilização e de mobilização social são ferramentas essenciais no combate à exploração sexual envolvendo crianças e adolescentes, uma vez que contribuem para formar opinião pública favorável às ações. Além disso, estimulam a participação de organizações públicas e privadas, formando e fortalecendo redes que auxiliem a prevenir e a coibir a exploração sexual infantojuvenil.

A proposta de intervenção em rede implica muito mais que somente a coordenação ou a articulação de diferentes recursos familiares, comunitários e institucionais. Implica tanto a aceitação de diversas modalidades de atenção quanto a demanda por uma construção coletiva de modelos, a fim de se compreender uma problemática altamente determinada por fatores ideológicos e culturais. Definitivamente, as redes sociais de proteção e atenção à infância e à adolescência e de combate à exploração sexual que contam com a participação de organizações públicas e privadas, de associações comunitárias, de empresas, de sindicatos e de outros movimentos sociais são a via mais eficaz para lograr uma resposta efetiva ao problema.

Cabe salientar que essas campanhas de sensibilização e mobilização social também visam estimular a prática da denúncia e reduzir a impunidade dos exploradores. Mais do que isso, têm como objetivo gerar serviços, políticas e programas de prevenção e de proteção às crianças e adolescentes (demanda prioridade e ações articuladas para a implementação de seus direitos). Ademais, tais campanhas devem ser cuidadosamente planejadas e executadas, de maneira que façam uso dos veículos de comunicação com o intuito de atingir todas as pessoas e conscientizá-las da gravidade do problema e das medidas para combatê-lo. Dessa forma, é importante ressaltar que os meios de comunicação exercem um papel determinante no combate à exploração sexual infantojuvenil, pois cabe a eles conscientizar a sociedade em geral sobre as causas e consequências do problema, reduzindo os níveis de tolerância social em relação ao mesmo.

Adiante, serão apresentados os dados estatísticos referentes às denúncias registradas nos seis anos em que a Abrapia operou o serviço, bem como uma análise qualitativa desses resultados. Cabe salientar que tais dados foram extraídos do livro Do marco zero a uma política pública de proteção à criança e ao adolescente - 080099-0500. Sistema Nacional de Combate ao Abuso e à Exploração Sexual Infantojuvenil, publicado pela Abrapia em 2004. 
Ao realizar uma análise das denúncias registradas ao longo dos seis anos de funcionamento do Sistema Nacional, constata-se que o uso do serviço pela população foi bastante irregular nos três primeiros anos (de 1997 a 1999). No primeiro ano, foram registradas 899 denúncias sobre exploração sexual infantojuvenil, considerando que a computação de denúncias sobre abuso sexual teve início apenas no ano 2000. Em 1998 e em 1999 houve uma queda considerável na utilização do serviço, tendo sido registradas, respectivamente, 218 e 134 denúncias.

Em contraste, a partir do ano 2000, o número de denúncias recebidas aumentou continuamente, saltando de 674, naquele ano, para 812, em 2001, e 1.819, em 2002. Além disso, no ano de 2003, considerando-se que o serviço operou somente até o mês de fevereiro, foram computadas 498 denúncias. Numa projeção para os 12 meses daquele ano a partir desse número, o total de denúncias poderia alcançar a marca de 2.900 .

Nesse sentido, do total de 5.054 denúncias recebidas entre fevereiro de 1997 e fevereiro de 2003, cerca de $82 \%$ foram realizadas por meio do atendimento telefônico gratuito (0800-99-0500). Entretanto, considerando que as denúncias também, podiam ser feitas pelo website da Abrapia, 14\% optou por este modo. Finalmente, os $4 \%$ restantes referem-se às denúncias realizadas por meio de outro número de telefone, pessoalmente e àquelas feitas a outra entidade, incluindo ainda denúncias sobre as quais não há informação quanto ao meio utilizado.

A região em que foi contabilizado o maior número de denúncias foi a Sudeste, com 2.023, o que corresponde a $40 \%$ do total. Em seguida vem a região Nordeste, com 1.143 denúncias (22,6\%); a região Sul, com 459 denúncias $(9,1 \%)$; a Centro-Oeste, com 324 denúncias $(6,4 \%)$, e a Norte, com 256 denúncias $(5,1 \%)$. Em relação a outras 849 denúncias não foi informada a região de origem. Observou-se também a prevalência do uso do serviço nas grandes regiões metropolitanas, especialmente, nas capitais, em detrimento das regiões afastadas dos grandes centros urbanos.

\section{Tabela 1 - Número acumulado de denúncias por recebimento, segundo as grandes regiões brasileiras - Fevereiro de 2003}

\begin{tabular}{lccccccc}
\hline $\begin{array}{l}\text { Grandes } \\
\text { Regiões }\end{array}$ & Total & $\mathbf{0 8 0 0}$ & Internet & $\begin{array}{c}\text { Outro } \\
\text { telefone }\end{array}$ & Pessoalmente & $\begin{array}{c}\text { Outra } \\
\text { entidade }\end{array}$ & $\begin{array}{c}\text { Não } \\
\text { informado }\end{array}$ \\
\hline Total & 5054 & 4170 & 710 & 17 & 9 & 4 & 144 \\
\hline Norte & 256 & 243 & 1 & 0 & 0 & 1 & 11 \\
\hline Nordeste & 1143 & 1121 & 1 & 1 & 1 & 1 & 18 \\
\hline Sudeste & 2023 & 1914 & 8 & 12 & 8 & 1 & 80 \\
\hline Sul & 459 & 439 & 2 & 0 & 0 & 1 & 17 \\
\hline Centro-Oeste & 324 & 311 & 0 & 1 & 0 & 0 & 12 \\
\hline Ignorada & 849 & 142 & 698 & 3 & 0 & 0 & 6 \\
\hline
\end{tabular}

Fonte: Abrapia (2004).

Em relação à natureza das denúncias, considerando as diversas formas de recebimento (tabela 1), constatou-se que 3.434, ou seja, 67,9\% do total, referiam-se à exploração sexual infantojuvenil, enquanto 1.620 (32\%) diziam respeito ao abuso sexual. Além disso, observou-se que a chamada "prostituição" de crianças ou adolescentes foi a forma de exploração sexual infantojuvenil com mais denúncias, cerca de $86 \%$ do total. Em seguida, tem-se a pornografia com crianças na internet, que corresponde a 6,0\% da totalidade de denúncias, enquanto o chamado turismo sexual abrange 3,7\% desse total. Além disso, existe a produção e venda de materiais pornográficos $(2,3 \%)$, além do tráfico de crianças e adolescentes com o fim de explorá-las sexualmente $(1,9 \%)$, conforme demonstrado no gráfico 1. 


\section{Gráfico 1 - Percentual de denúncias de exploração sexual no Brasil, conforme os diferentes tipos: Fevereiro de 1997 a fevereiro de 2003}

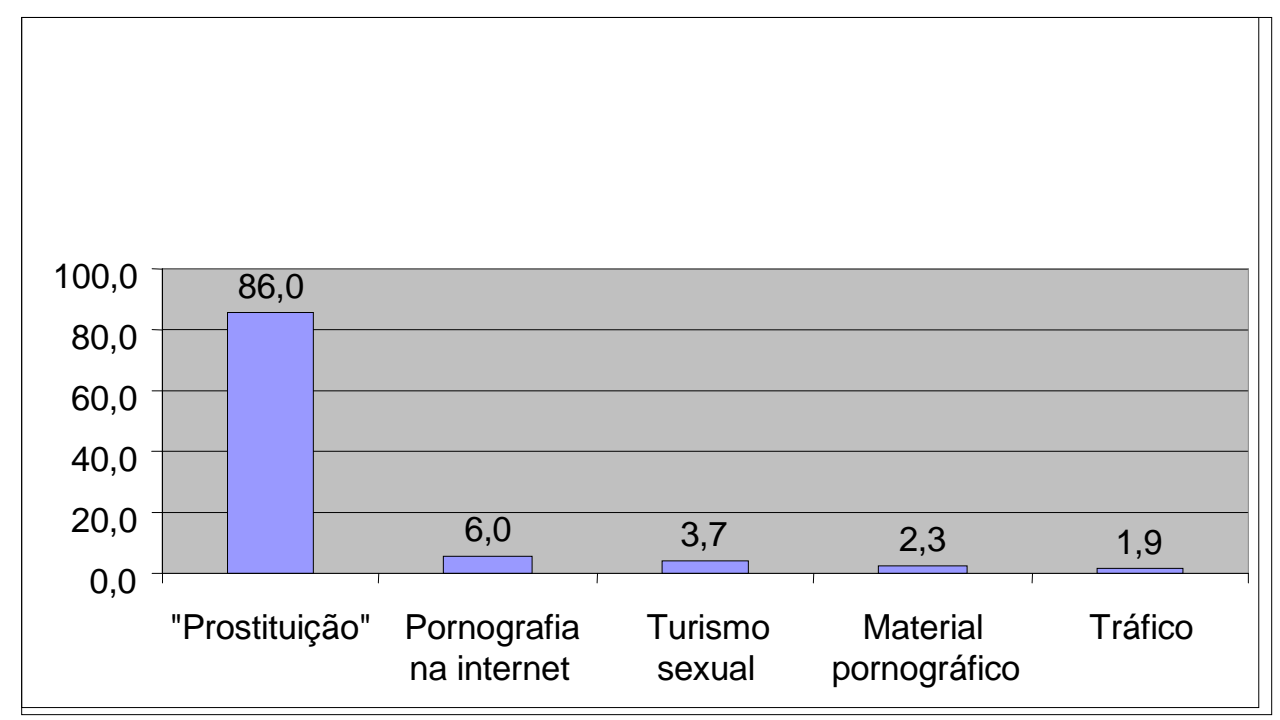

Fonte: Abrapia (2004).

Quanto ao local de exploração sexual infantojuvenil, a ocorrência em residência diz respeito à cerca de 1/3 dos casos denunciados, seguida por "ponto de concentração de crianças e adolescentes" $(14,2 \%)$, bares e restaurantes $(10,1 \%)$, boates $(7,4 \%)$, prostíbulos $(6 \%)$ e internet $(5,9 \%)$.

De acordo com os registros, meninas e adolescentes do sexo feminino são as vítimas mais frequentes nos casos de exploração sexual, correspondendo a cerca de $77 \%$ das ocorrências, enquanto as denúncias relativas ao sexo masculino correspondem a $8,1 \%$. Cabe salientar que em quase $23 \%$ dos casos denunciados não foi informada a faixa etária da vítima, que mais de $2 / 3$ das vítimas tinham entre 12 e 18 anos, que cerca de $5 \%$ delas tinham entre oito e 11 anos e $1 \%$, oito anos ou menos.

Entretanto, quando se altera o ângulo de visão e a atenção se volta para as pessoas denunciadas por exploração sexual, o sexo masculino predomina com $53,9 \%$ das denúncias recebidas, enquanto o sexo feminino representa $25,9 \%$. Nos outros $20,2 \%$ das denúncias, o sexo do agente explorador não foi informado.

Nos seis anos sob coordenação da Abrapia, antes de tornar-se uma política pública de âmbito federal, o Sistema Nacional contribuiu para que fossem alcançados alguns importantes resultados na área de proteção à infância e à adolescência, especificamente, no combate ao abuso e à exploração sexual infantojuvenil, quais sejam:

expedição de 31 autos de prisão em flagrante;

138 acusados de abuso ou exploração sexual infantojuvenil responderam a inquérito, sem prisão em flagrante;

em 259 casos denunciados, as investigações estavam em andamento; e

57 era o número de pessoas que, até aquele momento, respondiam a inquérito por denúncia anterior, aguardavam diligências ou que tinham sido encaminhadas a outra instância.

Sabe-se que esses resultados ainda não configuram uma situação ideal, mas que retratam a situação possível diante do estado da área de segurança pública nas diferentes unidades da Federação. Além disso, quando comparado ao total de denúncias, 
as investigações realizadas ou em realização e os resultados alcançados, em termos da responsabilização dos agentes delituosos, são baixos. No entanto, tal fato não oculta dois aspectos fundamentais. O primeiro é que, pela natureza dos delitos de abuso e exploração sexual infantojuvenil, de difícil visibilidade e quase sempre envolverem familiares das vítimas, estes dados representam um grande avanço em relação ao passado recente. Além disso, cada caso apurado serve como exemplo, demonstrando a disposição dos agentes públicos para enfrentar a questão. Assim, apesar de insuficientes, os resultados alcançados certamente contribuíram para inibir a ocorrência de diversos outros casos. (ABRAPIA, 2004)

Além dos resultados anteriormente apresentados, o Sistema Nacional trouxe importantes conquistas políticoinstitucionais, contribuindo significativamente para a questão da proteção à infância e à adolescência no Brasil. Entre elas, pode-se destacar:

reconhecimento em nível internacional do Brasil como o país responsável tanto pela elaboração de um Plano Nacional de Enfrentamento da Violência Sexual Infantojuvenil, quanto pela efetivação das ações propostas;

reconhecimento do Brasil como modelo para toda a América Latina, no que diz respeito à elaboração e execução de propostas referentes ao enfrentamento da violência sexual infantojuvenil;

estreitamento dos laços de compromisso da sociedade com o combate à violência sexual contra crianças e adolescentes;

maior comprometimento da mídia e maior aprofundamento da questão da violência sexual contra crianças e adolescentes em todo o país; e

ampliação do enfoque da violência sexual contra crianças e adolescentes, antes restrito ao chamado turismo sexual, abrangendo todas as formas de violência sexual, incluindo o abuso.

Apesar dessas conquistas e avanços, o Sistema Nacional de Combate ao Abuso e à Exploração Sexual Infantojuvenil enfrentou inúmeras dificuldades para sua implantação e execução, dentre as quais se destacam:

entraves no processo de monitoramento das denúncias, dificultando a mensuração dos resultados;

escassez de recursos para divulgação massiva e contínua do telefone de atendimento (0800-99-0500) e do Sistema Nacional. Cabe salientar que, apenas no ano do lançamento do telefone de atendimento, em 1997, a Embratur patrocinou uma campanha por três meses, focada no chamado turismo sexual. Dessa forma, percebe-se não somente a ausência de articulação por parte de alguns governos estaduais, como também por parte de algumas das principais entidades de reconhecida importância na luta contra a violência sexual da criança e do adolescente;

dificuldade dos órgãos de segurança do país em priorizar crianças e adolescentes, como determina o Estatuto da Criança e do Adolescente, reduzindo então o número de ações investigativas e repressivas;

dificuldade para estabelecer um planejamento conjunto no decorrer de todo o processo, por meio de reuniões periódicas entre a Abrapia e o Departamento da Criança e do Adolescente/SEDH/MJ, um de seus parceiros. Tais encontros teriam o intuito de estabelecer estratégias que influenciassem tanto na transposição quanto na eliminação dos gargalos encontrados nas ações do Sistema Nacional, como, por exemplo, o retorno das denúncias pelas instituições operadoras da Rede; e

resistência por parte de um número expressivo de pessoas em denunciar casos de abuso e exploração sexual infantojuvenil, principalmente, quando ocorridos no âmbito intrafamiliar.

\section{Plano Nacional de Enfrentamento da Violência Sexual Infantojuvenil}

Concomitantemente ao processo de consolidação da Rede de Enfrentamento da Violência Sexual contra crianças e Adolescentes, foi elaborado e aprovado o Plano Nacional de Enfrentamento da Violência Sexual 
Infantojuvenil, cujo objetivo era ser um instrumento de garantia e defesa do direito da criança e do adolescente. Mais especificamente, a proposta do Plano Nacional era criar, fortalecer e executar um conjunto articulado de ações voltadas para a proteção integral de crianças e adolescentes que já sofreram ou encontravam-se sob risco de sofrer alguma forma de violência sexual.

Para tanto, ficaram estabelecidas ações e medidas articuladas que permitissem a intervenção técnica, política e financeira no combate à violência sexual contra crianças e adolescentes. O Plano Nacional, que foi parte constituinte do compromisso assumido pelo governo brasileiro no Congresso de Estocolmo (1996), veio à luz apenas quatro anos depois do evento. Durante esse período, focado nas articulações necessárias - como, por exemplo, o financiamento e o estabelecimento de parcerias -, ocorreram três encontros nacionais (1997, 1998, 2000) dedicados à incorporação das diferentes ações-chave, tanto dos setores governamentais quanto dos nãogovernamentais, sendo a representação majoritária dos níveis federais, estaduais e municipais que, de alguma forma, estivesse vinculada às questões da violência sexual infantojuvenil.

Os encontros nacionais estiveram vinculados ao movimento internacional End Child Prostitution, Child Pornography and Trafficking of Children for Sexual Purpose (ECPAT), que teve participação decisiva no Congresso de Estocolmo e tornou-se um marco na luta contra a exploração sexual de crianças e adolescentes. Posteriormente, constitui-se uma rede global de organizações e indivíduos abrangendo dezenas de países.

O grande desafio lançado pelo ECPAT foi a criação de planos de ação dos países participantes, que deveriam ser elaborados conjuntamente por governo e sociedade. Dessa forma, o Brasil elaborou o seu Plano Nacional de Enfrentamento da Violência Sexual Infantojuvenil em 2000, durante o III Encontro ECPAT-Brasil, realizado em Natal. O plano brasileiro teve em sua composição seis eixos estratégicos, quais sejam: análise da situação, mobilização e articulação, defesa e responsabilidade, atendimento, prevenção e protagonismo infantojuvenil.

Para tanto, as condições objetivas para a sua efetivação eram baseadas na "exigibilidade do dever da família, da comunidade, da sociedade em geral e do poder público" (Constituição da República Federal do Brasil - Artigo 227, $\S 4^{\circ}$ e Estatuto da Criança e do Adolescente - Lei noํ․ 8.069/90).

Com isso, o Plano Nacional foi apresentado e deliberado pelo Conselho Nacional dos Direitos da Criança e do Adolescente (Conanda) em Assembleia Ordinária de 12 de setembro de 2000. Além disso, o plano se firmou como uma referência única nos âmbitos federal, estadual e municipal, para a implementação de medidas e o desenvolvimento de ações que pudessem assegurar o fim da violência sexual contra crianças e adolescentes, com base nos seis eixos estratégicos predefinidos.

Vale salientar ainda outro desdobramento importante do encontro realizado em Natal e que também está diretamente relacionado à causa: a instituição do dia 18 de maio (Dia Nacional de Combate ao Abuso e Exploração Sexual de Crianças e Adolescentes). Tal data tem a responsabilidade de funcionar como válvula propulsora de uma série de atividades, com o objetivo de conscientizar e mobilizar as pessoas em relação à violência sexual infantojuvenil. Deve ser ressaltado que o 18 de maio foi escolhido para marcar o tema por ter sido este o

dia da morte da menina de oito anos Araceli Cabrera Crespo, crime ocorrido em Vitória, no Espírito Santo [em 1973], por se tratar de um caso emblemático de violência extrema e total impunidade, já que os assassinos, pessoas influentes de importantes famílias da sociedade capixaba, não foram punidos. (RAMOS, 2000)

A fim de monitorar e avaliar a execução das ações contempladas no Plano Nacional, foi sugerida e aprovada a criação de um Fórum Nacional pelo Fim da Violência Sexual de Crianças e Adolescentes. Este congregaria diferentes instituições governamentais e da sociedade civil, além dos poderes Judiciário e Legislativo, do Ministério Público e dos conselhos dos Direitos das Crianças e do Adolescente, integrando-se a outros fóruns, como o Fórum Nacional da Criança e do Adolescente (Fórum DCA).

Atendendo à expectativa de fortalecimento da implementação do Plano Nacional, bem como seu monitoramento e avaliação, instituiu-se o Comitê Nacional de Enfrentamento da Violência Sexual Contra 
Crianças e Adolescentes. Assim, além dos processos de mobilização social, de disseminação dos conceitos e objetivos de serviços, o Plano Nacional teve importância relevante na sensibilização e articulação de diferentes líderes políticos, governamentais e internacionais, numa ampla advocacia social.

Por fim, o estabelecimento de parcerias estratégias com a Abrapia no âmbito do Plano Nacional de Enfrentamento da Violência Sexual Infantojuvenil foi essencial para que este atingisse seus objetivos. Nesse sentido, tal parceria visou não apenas à criação de mecanismos de troca de informações sobre o tema, mas também à adoção de instrumentos facilitadores da notificação das denúncias de violência sexual e da articulação desse serviço com os demais órgãos de defesa e responsabilidade.

\section{Considerações finais}

Este artigo tratou de duas ações de combate à exploração e abuso sexual de crianças e adolescentes. A perspectiva adotada foi a de que proteger as crianças e os adolescentes significa afastá-los de situações em que estejam suscetíveis ao problema, além de assegurar-lhes direitos básicos como saúde, educação, atenção integral e convivência familiar e comunitária. Dessa forma, foi analisado o impacto social da implementação da ação de proteção a crianças e adolescentes vítimas desse tipo de violência.

Observou-se ainda, que iniciativas de proteção são, geralmente, de responsabilidade das secretarias voltadas à assistência social, principalmente por parte das prefeituras. Porém, deve-se considerar que soluções intersetoriais, com trabalho articulado entre os diversos setores da sociedade, ultrapassam barreiras expostas e possibilitam uma vida digna e saudável a milhares de crianças e adolescentes. Em outras palavras, ao invés de realizar programas somente de atendimento ou somente de prevenção, priorizam-se programas integrados que objetivem: prevenção, atendimento, controle social e serviços de abrigamento, entre outros.

Todavia, é preciso conscientizar-se de que trabalhos envolvendo ações coletivas, certamente, enfrentam dificuldades que precisam ser trabalhadas, como por exemplo, a de garantir repasse de informações e a troca de experiências. Entretanto, esse tipo de trabalho somente atingirá seu objetivo quando as autoridades brasileiras e a sociedade civil envolverem-se política e economicamente num esforço para assumir esse compromisso comum. Portanto, compete também aos cidadãos a responsabilidade pela busca de soluções, pelo engajamento nesse esforço e pelo envolvimento concreto de todos aqueles que acreditam nos direitos humanos e na melhoria do país.

Felizmente, o histórico de ações empreendidas pelo poder público e ratificadas pela sociedade civil brasileira demonstram destaque na agenda pública brasileira no que diz respeito ao combate à exploração sexual de crianças e adolescentes. É importante salientar que o envolvimento da sociedade é essencial tanto a esse combate quanto à punição dos envolvidos e responsáveis pelo crime.

A partir dos aspectos levantados neste artigo, observou-se que a questão da exploração sexual de crianças e adolescentes é multifacetada, com implicações em diversos campos: econômico, social, político, moral, legal, criminal etc. Nesse sentido, vale ressaltar que tal questão é agravada por um programa do atual governo, o Programa de Aceleração do Crescimento (PAC), devido à dificuldade recorrente de grandes obras de infraestrutura pelo país, sobretudo, por causa da pobreza.

Observa-se grande preocupação do governo com projetos de desenvolvimento econômico, e não somente no caso de obras públicas, pois tendem a intensificar a exploração sexual. É importante conscientizar-se de que, em outros estados, a partir da preocupação com o aumento dos casos de exploração sexual infantojuvenil nos canteiros das obras do PAC, o governo vem lançando planos de prevenção às margens das obras, os quais consistem na maior divulgação do disque 100 e no fortalecimento da rede de atendimento local e das políticas sociais.

No caso da cidade do Rio de Janeiro, em paralelo aos canteiros de obras, serão construídos canteiros sociais que darão novas perspectivas aos moradores, considerando que estes participarão de cursos de capacitação em diversos setores. Além disso, essa ação social possibilita uma atuação mais efetiva do governo, em seus vários 
níveis, em programas que apresentam a melhoraria da qualidade de vida da população como seu objetivo principal.

Em suma, é importante ter ciência de que ações isoladas por parte do poder público não são suficientes para minimizar os efeitos desse crime cometido contra crianças e adolescentes. Por isso, acredita-se que deve haver um maior comprometimento por parte da sociedade civil. Nesse caso, objetiva-se transformar os cidadãos em dificultadores e não facilitadores da atividade. Para tanto, a sociedade, em sua totalidade, deve compreender não apenas a importância da denúncia, mas também a dimensão do problema, a fim de que políticas públicas sejam formuladas e efetivamente implementadas visando à erradicação da exploração sexual infantojuvenil. 


\section{Referências}

ABRAPIA - Associação Brasileira Multiprofissional de Proteção à Infância e à Adolescência. Do marco zero a uma política pública de proteção à criança e ao adolescente - 0800-99-0500. Sistema Nacional de Combate ao Abuso e à Exploração Sexual Infantojuvenil. Rio de Janeiro: Abrapia, 2004.

BRASIL. Congresso. Senado. Constituição da República Federativa do Brasil. Brasília, DF, 1988. . Lei Federal no 8.069/90. Estatuto da Criança e do Adolescente.

. Ministério da Justiça. Plano Nacional de Enfrentamento da Violência Sexual Infantojuvenil. Brasília, DF, 2006.

DOS SANTOS, Benedito Rodriguez. Contribuições para um balanço das campanhas de combate ao abuso e exploração sexual de crianças e adolescentes no Brasil. In: LIBÓRIO, Renata Maria Coimbra; SOUSA, Sônia M. Gomes (Org.). A exploração sexual de crianças e adolescentes no Brasil: reflexões teóricas, relatos de pesquisas e intervenções psicossociais. São Paulo: Casa do Psicólogo; Goiânia: Universidade Católica de Goiás, 2004.

FALEIROS, Vicente de Paula (Coord.). Fundamentos e políticas contra exploração e abuso sexual de crianças e adolescentes. Relatório de estudo. Brasília, DF: Ministério da Justiça/Cecria, 1997.

GRAU, Nuria Cunill. Repensando o público através da sociedade: novas formas de gestão pública e representação social. Tradução: Carolina Andrade. Brasília, DF: Enap, 1998.

HAZEU, Marcel; FONSECA, Simone. Exploração e violência sexual contra crianças e adolescentes no Pará. In: LEAL, Maria de Fátima Pinto; CÉSAR, Maria Auxiliadora (Org.). Indicadores de violência intrafamiliar e exploração sexual comercial de crianças e adolescentes. Brasília, DF: Cecria, 1998.

JACOBI, Pedro Roberto. Políticas sociais e ampliação da cidadania. 2.ed. Rio de Janeiro: FGV, 2002.

LEAL, Maria de Fátima P.; CÉSAR, Maria Auxiliadora (Org.). Estudo analítico do enfrentamento da exploração sexual comercial de crianças e adolescentes no Brasil - ESCCA (Período 1996-2004). Brasília, DF: Violes/SER/UnB, 2005.

LEAL, Maria Lúcia Pinto. A mobilização das ONGs no enfrentamento à exploração sexual comercial de crianças e adolescentes no Brasil. Tese (Doutorado em Serviço Social) - Pontifícia Universidade Católica (PUC), São Paulo, 2001.

Globalização e exploração sexual comercial de crianças e adolescentes. Rio de Janeiro: Save the Children, 2003. Mimeografado.

OIT/IPEC - Programa de Prevenção e Eliminação da Exploração Sexual Comercial de Crianças e Adolescentes na Tríplice Fronteira Argentina/Brasil/Paraguai. <http://www.oit.org.pe/ipec/pagina.php?seccion=63\&pagina=284>. Acesso em: 26 jun. 2007.

PAMPOLS, Carlos Feixa. Glossário de exploração sexual comercial de crianças e adolescentes. OIT/IPEC. Disponível em: <http://white.oit.org.pe/ipec/pagina.php?pagina=284\&gloLetra=l>. Acesso em: 2 nov. 2007.

RAMOS, Eleonora. Histórico sobre a criação do Dia Nacional de Combate ao Abuso e Exploração Sexual de Crianças e Adolescentes. 2000. Disponível em: <http://www.cedeca.org.br/PDF/historico_eleonora_ramos.pdf>. Acesso em: 6 dez. 2007.

REPORTAGEM ESPECIAL. Abuso sexual de crianças e adolescentes: um mal frequentemente doméstico. 2005. Disponível em: <http://www.camara.gov.br/internet/radiocamara/default.asp?selecao=MAT\&Materia=25402>. Acesso em: 26 mar. 2007.

SILVA, Ana Paula; BLANCHETTE, Thaddeus. Nossa Senhora da Help: sexo, turismo e deslocamento transnacional em Copacabana. Cadernos Pagu, Campinas, n.25, 2005.

SOUZA, Celina. Políticas públicas: conceitos, tipologias e subáreas. Trabalho elaborado para a Fundação Luís Eduardo Magalhães. São Paulo, 2002.

SUBGROUP against the sexual exploitation of children. Semantics or substance? Towards a shared understanding of terminology referring to the sexual abuse and exploitation of children. In: GLOSSÁRIO de exploração sexual comercial de crianças e adolescentes. 2005. Disponível em: <http://white.oit.org.pe/ipec/pagina.php?pagina=284\&gloLetra=A\#Abuso \%20Sexual>. Acesso em: 20 fev. 2008.

TENÓRIO. Fernando G. Responsabilidade social empresarial: teoria e prática. Rio de Janeiro: FGV, 2004.

VIANNA, Sólon (Coord.) et al. Orçamento criança e orçamento participativo: a experiência brasileira. Brasília/DF: Unicef, 2003. 